CUADERNOS DE ESTUDIOS GALLEGOS, LXVI Núm. 132 (enero-diciembre 2019), págs. 373-393

ISSN: $0210-847 \mathrm{X}$

https://doi.org/10.3989/ceg.2019.132.12

\title{
ENRIQUE HERVADA GARCÍA SAMPEDRO: EL MÉDICO CORUÑÉS DE LOS POBRES
}

\author{
Sonia González Castroagudín \\ Servicio Galego de Saúde \\ ORCID iD: https://orcid.org/0000-0002-4748-6277 \\ María del CARMen MaNRESA LóPEZ \\ Servicio Galego de Saúde \\ ORCID iD: https://orcid.org/0000-0002-8248-578X \\ Fernando J. Ponte Hernando \\ Universidad de Santiago de Compostela \\ ORCID iD: https://orcid.org/0000-0002-1581-8775 \\ Raquel GonzÁLEz Castroagudín \\ Servicio Galego de Saúde \\ ORCID iD: https://orcid.org/0000-0001-5322-070X
}

Copyright: (C) 2019 CSIC. La edición electrónica de esta revista se distribuye bajo los términos de una licencia de uso y distribución Creative Commons Reconocimiento 4.0 Internacional (CC BY 4.0).

Cómo citar/Citation: Sonia González Castroagudín, María del Carmen Manresa LóPez, Fernando J. Ponte Hernando, Raquel González Castroagudín, "Enrique Hervada García Sampedro: el médico coruñés de los pobres", Cuadernos de Estudios Gallegos, 66, núm. 132 (2019), págs. 377-399, https://doi.org/10.3989/ceg.2019.132.12 


\title{
ENRIQUE HERVADA GARCÍA SAMPEDRO: EL MÉDICO CORUÑÉS DE LOS POBRES
}

\begin{abstract}
RESUMEN
Enrique Hervada García Sampedro fue un médico volcado completamente en su trabajo. Destacó por su labor humanitaria y por su dedicación incansable a los desfavorecidos. Gran parte de su labor la realizó en la ciudad de A Coruña. Fue Profesor Ayudante en la Facultad de Medicina de Santiago de Compostela y realizó varios viajes y estancias en París, donde se formó al lado del eminente urólogo Joaquín Albarrán, catedrático de Vías urinarias en la Facultad de Medicina de París, desde 1906. Trabajó gratuitamente en el dispensario antituberculoso de la Calle del Sol y en el Sanatorio Marítimo de Oza, al mismo tiempo que atendía su consultorio de la Calle Real. El Dr. Hervada realizó aportaciones de gran interés al estudio etiológico y epidemiológico de la tuberculosis y a los métodos clínicos y complementarios del diagnóstico, divulgando técnicas exploratorias para la detección precoz, como la radiología. Realizó además un gran trabajo de investigación titulado «La lucha antituberculosa en Galicia» y publicado en 1924, donde analizaba, entre los años 1910 y 1921, la evolución de la enfermedad y la mortalidad, relacionándola, sobre todo, con las medidas higiénico-dietéticas llevadas a cabo durante la enfermedad.

PALABRAS ClaVE: tuberculosis, infección, alimentación, pobreza, higiene.
\end{abstract}

\section{ENRIQUE HERVADA GARCÍA SAMPEDRO: O MÉDICO CORUÑÉS DOS POBRES}

\section{RESUMO}

Enrique Hervada García Sampedro foi un médico dedicado completamente co seu traballo. Destacou pola súa labor humanitaria e pola dedicación incansable ós desfavorecidos. Gran parte do seu traballo levouno a cabo na cidade da Coruña. Foi Profesor Axudante na Facultade de Medicina de Santiago de Compostela, e realizou varias viaxes a París, onde se formou á beira do eminente urólogo Joaquín Albarrán, catedrático de Vías urinarias na Facultade de Medicina de París, dende 1906. Traballou de maneira gratuita no dispensario antituberculoso da Rúa Sol e no Sanatorio Marítimo de Oza, ó mesmo tempo que asistía no consultorio da Rúa Real. O Dr. Hervada fixo aportacións de gran interese ó estudio etiolóxico e epidemiolóxico da tuberculose, ós métodos clínicos e complementarios do diagnóstico, divulgando técnicas exploratorias para a detección precoz, como a radioloxía. Realizou ademais un gran traballo de investigación «La lucha antituberculosa en Galicia» publicado en 1924, onde analizou, entre os anos 1910 e 1921, a evolución da enfermidade e a mortalidade, relacionándoa, sobre todo, cas medidas hixiénico-dietéticas levadas a cabo durante a enfermidade.

PALABRAS ClAVE: tuberculose, infección, alimentación, pobreza, hixiene.

\section{ENRIQUE HERVADA GARCÍA SAMPEDRO: THE POOR MAN'S DOCTOR FROM CORUÑA}

\begin{abstract}
Enrique Hervada García Sampedro was a medical doctor completely dedicated to his work. He stood out for his humanitarian labour and for an untiring dedication to the disadvantaged. Much of his work was done in the city of A Coruña. He was Assistant Professor in the Faculty of Medicine of Santiago de Compostela and made several study stays in Paris, where he formed by the side of the eminent urologist Joaquín Albarrán, chair of urinary tract in the Faculty of Medicine of Paris, since 1906. He worked for free in the antituberculous dispensary of Sol Street, and in the Maritime Sanatorium of Oza, while, at the same time, attended patients at his consultory of the Real Street. Dr. Hervada made contributions of great interest to the etiological and epidemiological study of tuberculosis, clinical and complementary diagnostic methods, and disseminated exploratory techniques for early detection, such as the use of radiology. He also carried out a great research work «The tuberculosis fight in Galicia» published in 1924, in which he analyzes, between 1910 and 1921, the evolution of the disease and its mor-tality relating, above all, to the hygienic-dietary measures taken during the illness. KEY WORDS: tuberculosis, infection, feeding, poverty, hygiene.
\end{abstract}



nrique Hervada García Sampedro ${ }^{1}$ nació en el número 58 de la calle de San Andrés de A Coruña, a las once y media de la noche del 10 de junio de 1883, y fue bautizado cinco días más tarde en la Iglesia parroquial de San Nicolás, con los nombres de Enrique y Jerónimo.

\section{FORMACIÓN}

Tras la primera enseñanza, cursó estudios de bachillerato en el Instituto Eusebio da Guarda, de La Coruña, con muy buenas calificaciones, debido a su clara inteligencia, a su esfuerzo y voluntad, virtud que le acompañó a lo largo de toda su vida, dedicando muchas horas al estudio. Cursó la carrera de Medicina en la Facultad de Santiago

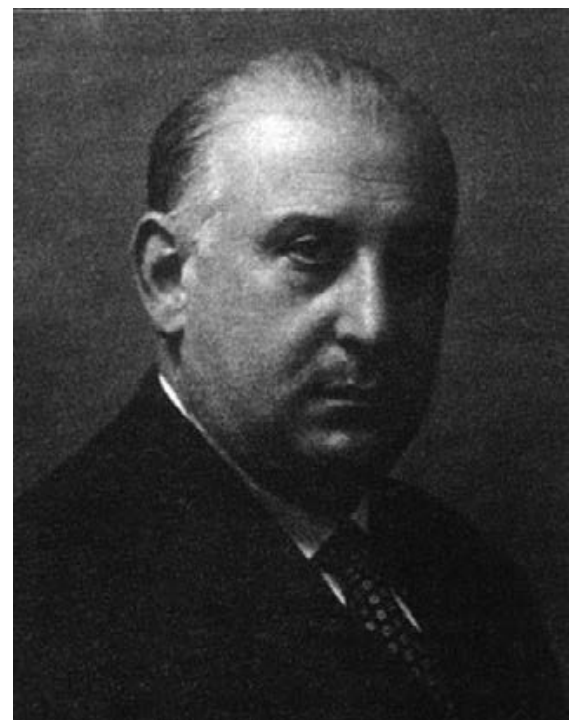

Fig. 1. Dr. Enrique Hervada García Sampedro. Imagen obtenida de Albúm da Ciencia. Consello da Cultura Galega. de Compostela (1898-1903)', obteniendo brillantes calificaciones y, en 1905, se licenció en la Facultad de San Carlos de Madrid, con Sobresaliente. Fue declarado totalmente excluido del servicio militar en junio de $1903^{3}$ sin que sepamos la causa. Obtuvo el grado de doctor, también en Madrid, en el año 1906, siendo premiada su tesis titulada La Sifilis ignorada. Fue en el año 1915-1916 cuando le entregaron el acta de Doctor.

\footnotetext{
1 El lector que desee ampliar datos sobre este estudio puede consultar la tesis doctoral de Sonia GonzÁLEZ Castroagudín, Sifilis, tuberculosis y alimentación, la obra de Enrique Hervada García Sampedro (18831953) y la salud materno-infantil, Universidade da Coruña, 2017, inédita, disponible en $<$ https://ruc.udc.es/ dspace/handle/2183/19155>. El director de la misma fue el tercero de los coautores de este artículo.

2 Archivo Histórico Universitario de Santiago, Leg. 621, Expediente 7.

3 Gaceta de Galicia. Diario de Santiago (07-06-1903), pág. 2.
} 
Fue Profesor Ayudante en la Facultad de Medicina de Santiago de Compostela y realizó varios viajes a París, donde se formó al lado del urólogo español de fama mundial Joaquín Albarrán ${ }^{4}$, [Sagua la Grande (Cuba) 1860 - París 1912] catedrático de Vías urinarias en la Facultad de Medicina de París desde 1906.

Fue muy fructífero este viaje para el Dr. Hervada, ya que participó activamente en muchas actividades en la capital francesa y, además, amplió conocimientos en distintas materias.

Hervada obtuvo el diploma del Hospital Saint Louis y el título de Dermatólogo, por un curso de Clínica de Enfermedades Cutáneas y Sifilíticas 5 , tal y como nos comentaba su nieto, ya fallecido, el Prof. Dr. D. Arturo Rodríguez Hervada en una entrevista personal. Asimismo, obtuvo otro Diploma de la Facultad de Medicina de París por un curso de Otorrinología y otro de L'Hôtel Dieu'.

Se convertiría, además, en miembro correspondiente de la Sociedad de Dermatología y Sifiliografía de París, «como recompensa a unos trabajos técnicos sobre el 606» ${ }^{7}$.

Regresó a La Coruña después de su paso por París y, en 1908, abrió su consultorio en la calle Real y se dedicó a lo que siempre le había gustado, ser médico general o de cabecera, el verdadero médico de familia. En agosto de ese año renunció a su plaza de médico de la sociedad de Socorros mutuos «La Conciliadora», siendo nombrado en su lugar el Dr. Martín Bescansa ${ }^{8}$.

\section{ACTIVIDAD PROFESIONAL}

Con veinticinco años, Enrique Hervada ya se había establecido en La Coruña y, pese a su juventud, su consultorio de la calle Real estaba ya muy concurrido. Su sólida formación profesional le permitió ir sustituyendo, sagazmente, el ojo clínico y el examen de pulso y de la lengua, que constituían, en aquellos tiempos, la trilogía obligada del facultativo, por nuevas y modernas exploraciones y mé-

\footnotetext{
4 Joaquín María Albarrán y Domínguez, eminente urólogo nacido en 1860 en la Cuba española en Sagua La Grande. En Barcelona cursó el bachillerato y la licenciatura. Hizo el doctorado en la Universidad Central de Madrid. Contaba tan sólo con 18 años al graduarse. En 1878 viajó a París, donde trabajó y estudió con importantes médicos como Guyón. En los inicios de su carrera Albarrán se dedicó a los campos de la microbiología y la anatomía patológica, pero más tarde prefirió la urología donde realizó importantes contribuciones. A los 42 años, era Profesor agregado y, en 1894, cirujano jefe de los hospitales de París. Por último, en 1898 se le designaba vicepresidente de la Sociedad Francesa de Urología. M. PÉREZ-Albacete, “Joaquín María Albarrán y Domínguez (1860-1912). En el centenario de su fallecimiento”, Actas urológicas españolas, vol. 36, núm. 4 (2012), págs. 246-51.

5 Arturo Rodriguez Hervada, Del tiempo de los odios y las iras. La educación de un niño de la guerra civil, [s. 1.], Ed. Bubok, 1936-1956.

6 Alfonso Gonzalez Catoyra, Biografias coruñesas, La Coruña, Graf. Galaico, 1990, pág. 303-308

7 La Región (05-05-1911), pág. 3.

8 "Nombramientos", El Norte de Galicia. Diario político y de información (29-08-1908), pág. 2.
} 
todos analíticos que hacían más fáciles, y sobre todo más exactos, los diagnósticos de los pacientes ${ }^{9}$.

Con tan valiosos elementos al servicio de su clara inteligencia y su extraordinaria cordialidad para el enfermo, la reputación de Enrique creció rápidamente.

\section{DESINTERÉS ECONÓMICO ASISTIENDO A LAS CLASES MÁS DESFAVORECIDAS}

El móvil económico, sin embargo, nunca contó para él en el ejercicio de su actividad profesional, porque era un verdadero enamorado de su carrera. Así se explica que, a pesar del prestigio adquirido, continuara, durante muchos años, prestando sus servicios a una Sociedad de asistencia, que abonaba cincuenta céntimos mensuales por socio, y su colaboración gratuita con el Dispensario antituberculoso de la calle del Sol y el Sanatorio Marítimo de Oza. En los últimos años de su vida tenía abonados que le pagaban cinco pesetas por mes, a los que asistía con atención y cariño, gastando bastante más en sus desplazamientos en taxis, para llegar a sus domicilios.

La fama del doctor Hervada, como la del doctor Marañón, se basó, aparte de en su «ojo clínico» y su inteligencia, en una extremada cordialidad con los pacientes, que veían en él a un amigo y a un consejero. A ello se unió su desinterés económico. En unos tiempos difíciles, donde no existía ni seguridad social, ni pensiones, ni otras ayudas asistenciales, D. Enrique nunca cobró a personas de escasos medios económicos. Incluso, en muchos casos, les dejaba un donativo debajo de la almohada y, si cobraba, era una cantidad simbólica, como los cincuenta céntimos que la citada sociedad asistencial le pagaba al mes por cada abonado. Por esta máxima implicación con las clases más desfavorecidas, le llamaban el médico amado por los pobres.

Su total desprendimiento y su gran amor por los enfermos explican que, después de haber sido uno de los médicos que más trabajó en La Coruña, no hubiese llegado a constituir un modesto patrimonio. Tanto que, cuando falleció, su familia tuvo dificultades económicas para atender los gastos de su entierro, que fueron condonados, al no recibir factura alguna, por la buena gente de todos los servicios: funeraria, floristas, taxistas, Ayuntamiento, esquelas, prensa, etc. E incluso un cliente agradecido le regaló el nicho en San Amaro para su eterno descanso.

Su entierro fue una de las manifestaciones populares más grandes que recuerda la ciudad en el siglo XX. Y es que los coruñeses entendieron que, con su fallecimiento, no moría sólo un médico desinteresado, bondadoso, humanista, popular e íntegro, sino una forma de entender la medicina, al modo y manera del sacerdocio.

\footnotetext{
9 González Catoyra, Biografías coruñesas..., pág. 304.
} 


\section{HervadA. Hombre DE CIENCIA}

Enrique Hervada fue realmente un adelantado de la medicina coruñesa. Siempre utilizó los procedimientos más modernos y los últimos métodos en boga como consecuencia de sus repetidos cursos de formación en París y su inquietud por el saber. Como lo demuestra que fue el primer galeno que empleó el Salvarsán en el tratamiento de la sífilis en La Coruña, el primero que tuvo Rayos X y el primero en utilizar el neumotórax terapéutico y las sales de oro en el tratamiento de la tuberculosis ${ }^{10}$.

\section{Uso de Rayos X}

Sería en 1919, cuando Enrique Hervada comenzase a trabajar con sus propios Rayos X, en su consultorio de La Coruña.

Además de usar sus equipos en la consulta privada, también trabajó durante más de 19 años como Médico Radiólogo de la Beneficencia Municipal de La Coruña, siendo nombrado el 14 de diciembre de 1921, no tomando posesión hasta el 1 de abril de 1922. Debido a que en el Hospital Municipal no contaban con equipos propios de Rayos X, era Hervada quien realizaba la asistencia de radioscopia, radiografía y radioterapia a esos pacientes, a cambio de una indemnización que, inicialmente, fue de 1.975 pesetas anuales, en concepto de gastos y mantenimiento de los equipos.

Hervada seguiría trabajando en la Beneficencia hasta el 15 de abril 1941, fecha de su jubilación, que había solicitado al Sr. Alcalde el 27 de marzo, por presentar intolerancia e hipersensibilidad al manejo de los Rayos X, que le provocaban vértigos, hipertensión arterial y radiodermatitis en las manos.

\section{Aplicación del Salvarsán para el tratamiento de la sifilis}

Sabemos que, en octubre de 1910, regresó a La Coruña, tras dos meses en París estudiando el Salvarsán o «606» ${ }^{11}$. De modo inmediato, comenzó su labor divulgativa sobre el asunto, dando una conferencia en la Reunión de Artesanos, el 30 de octubre, en la que «hizo un retrato minucioso de los casos que ha visto tratar en París al doctor Milián» ${ }^{12}$. En dicha conferencia indicó que durante la lactancia era preferible someter previamente a la madre a una inyección de 606, en vez de inyectarlo directamente al niño ${ }^{13}$. Hervada consideró el Salvarán o

\footnotetext{
${ }^{10}$ González Catoyra, Biografias coruñesas..., pág. 305.

11 "Nuevo tratamiento de la sífilis", La Región, Diario independiente (20-10-1910), pág.3.

12 “Conferencia del Dr. E. Hervada”, La Región (01-11-1910), pág.1.

13 “Conferencia del Dr. E. Hervada”, El Diario de Pontevedra (02-11-1910), pág. 2.
} 
«606» un gran descubrimiento, que lo fue, y, por tanto, lo aplicó a distintos pacientes, obteniendo buenos resultados.

\section{Neumotórax terapéutico}

Enrique Hervada quiso dar a conocer las aplicaciones del neumotórax artificial, según su experiencia personal en el manejo de esta técnica.

En aquellos momentos la práctica del neumotórax terapéutico era de excepción. Consistía en colapsar temporalmente un pulmón, mediante la inyección controlada de aire entre las dos pleuras, para cerrar así las cavernas tuberculosas y favorecer su cicatrización. Hervada lo realizó en bastantes ocasiones.

En una de sus publicaciones titulada: Indicaciones del pneumotórax artificial en las hemoptisis tuberculosas, comentó distintos casos en los que aplicó el neumotórax con resultado favorable, mejorando considerablemente el paciente. Verdes Montenegro, Gil Casares y Casimiro Martínez, entre otros muchos autores españoles y extranjeros, apoyarían esta práctica terapéutica.

\section{HERVADA ACADÉMICO}

En 1920 Enrique Hervada comenzó su andadura en la Real Academia de Medicina y Cirugía de Galicia y Asturias. En este año presentó su Discurso de ingreso, La Tuberculosis Obscura, en abril. Son un total de 69 cuartillas mecanografiadas, con citas a pie de página, donde relataba algunos casos asistidos por él, durante quince años de labor asistencial a pacientes tísicos y sifilíticos.

Desde su mismo año de ingreso en la Academia, Hervada comenzó una importante labor como miembro de la misma. Contribuyó a la vida de la institución con numerosas conferencias y participó con intensidad en las actividades llevadas a cabo.

Estas son algunas de las conferencias impartidas por el Dr. Hervada:

- Los dolores braquiales de origen cerebral.

- Las manifestaciones abdominales de la bacilosis latente.

- Estigmas somáticos de origen tuberculoso. El Infantilismo.

- Los síntomas que molestan al tuberculoso.

- Fiebre y febrícula de origen tuberculoso.

En 1933, ocupó el cargo de Secretario Perpetuo, tal y como recoge José Carro Otero $^{14}$.

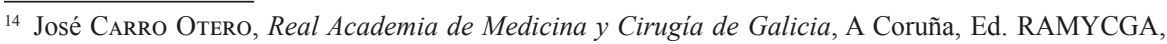
2002, pág. 52.
} 
Ocupó este cargo hasta su fallecimiento, en 1953: fueron, desde su ingreso en 1920, 33 años de importante labor en esta Institución.

\section{La Guerra Civil}

Fueron los años de la Guerra Civil para el Dr. Hervada verdaderamente complicados. Tal y como recoge su nieto el Dr. Arturo Rodriguez Hervada en el libro Del tiempo de los odios y las iras. Enrique Hervada era republicano y liberal. Afiliado a la izquierda y simpatizante de los partidos extremistas en cuyos locales impartía conferencias. El verano de 1936 el Dr. Hervada, junto con su familia, tuvo que trasladarse a Betanzos, dónde vivía un hermano suyo, para así evitar peligros y complicaciones que se podían desencadenar en A Coruña, debido a su ideología política.

Nuestra casa estaba en el ensanche. La Coruña era entonces -verano 1936una ciudad con límites urbanos bien definidos. La familia materna había abandonado la casa de la calle Real porque estaba situada junto al Gobierno Civil y mi abuelo dijo que si había lío este edificio sería el primero que iban a bombardear. La familia de mi tía Maruja vivía también en esa misma calle. Su marido, el tío Pepe, era teniente de la Guardia Civil y jugó un papel muy importante en la conspiración familiar. En un par de horas nuestra casa se llenó con toda la familia de mi madre, que eran siete hermanos. [...] Pasados los primeros días del trauma inicial, la familia de mi madre se dio cuenta que la cosa iba en serio y empezó a preocuparse por la suerte de mi abuelo el Dr. Enrique Hervada García-Sampedro, que era republicano y liberal. En 1931 al proclamarse la II República, el pueblo se lanzó a la calle con grandes muestras de júbilo. Cuando la turba alegre de manifestantes bajaba por la calle Real, la más céntrica de la ciudad, se encontraron con mi abuelo que venía calle arriba; el pueblo lo tomó en sus hombros y así fue llevado por unos minutos. Cinco años más tarde había gente que recordaba este trivial episodio. Afortunadamente, mi tío Pepe fue nombrado jefe de la Guardia Civil de Betanzos, un bello pueblo situado a veinticinco kilómetros de la ciudad, lo que motivó que la familia entera de mi madre, nos fuésemos a vivir allí con él. De esta manera mi abuelo y mi padre, que al parecer también tenía sus enemigos, estaban protegidos. En Betanzos nos instalamos en la casa de un hermano de mi tío que se encontraba fuera con su familia. Allí pasamos el verano de 1936. De este tiempo recuerdo que nos llevaban en un automóvil a la playa del Pedrido, una de las pocas de la región donde la temperatura del agua es tolerable para el ser humano.

El 10 de octubre de 1936, Florentino González Valles, Gobernador Civil de La Coruña, ordenó la depuración de los miembros de la Inspección Provincial de Sanidad (Proceso número 42.053) que fue llevado a cabo por dos policías y un 
brigada de La Guardia Civil. Uno de los miembros de dicha organización era mi abuelo, el informe sobre él dice así:

HERVADA GARCIA, ENRIQUE. Afiliado a la izquierda, simpatizante de los partidos extremistas en cuyos locales daba conferencias culturales. Al saberse el triunfo del Frente Popular y delante de la multitud, se subió a un camión desde donde felicitó a la muchedumbre por tan resonante triunfo, pero en más de una ocasión contuvo a las masas, para que no cometieran desmanes ${ }^{15}$.

Pasado el verano, y en vista de que las cosas por A Coruña estaban más tranquilas, deciden regresar.

\section{PRODUCCIÓN CIENTÍFICA}

La producción científica de Hervada comenzó con su tesis doctoral, La Sifilis Ignorada (1906), que sería publicada años después de su lectura. En ella se estudiaban diversos casos, de difícil interpretación clínica, de sífilis ignorada, latente, adquirida o heredada, y afirmaba que el laboratorio era el único medio que existía para diagnosticar como sífilis ciertas alteraciones funcionales que no podían ser diagnosticadas únicamente por los síntomas clínicos ${ }^{16}$.

Estudió concretamente, en esta tesis, 18 casos descritos en las 76 páginas en las que desarrolla su trabajo de investigación. Todos ellos coinciden en que los pacientes que consultaban, en un principio, no observaron ninguna manifestación de chancro y, sin embargo, presentaban lesiones o afasias que, estudiadas en profundidad, manifestaron infección sifilítica.

Comentaba, además, que, tanto la sífilis como la tuberculosis, constituían etiológicamente los dos tercios de la patología humana de aquel momento.

Hervada estudió a fondo este tema, debido a la alta incidencia de sífilis que, por aquel entonces, se presentaba. Ya que, según decía su profesor, Tomás Maestre: «La humanidad está sifilizada».

Son numerosas las publicaciones del tisiólogo coruñés a lo largo de su carrera profesional. Sus obras muestran un incansable interés por mejorar las condiciones de las clases populares, a través de su trabajo como médico y publicista.

\footnotetext{
15 Rodriguez Hervada, Del tiempo de los odios y las iras..., págs 35-54.

16 Ánxela Bugallo, "Enrique Hervada García-Sampedro", en Álbum da Ciencia, Culturagalega.org. Consello da Cultura Galega, 2012. <URL:http://www.culturagalega.org/albumdaciencia/detalle. php?id=251>. [Consulta: 19/03/2017].
} 
Hervada trabajó intensamente como divulgador de temas médicos a través de la Universidad Popular ${ }^{17}$ y también en La Voz de Galicia, con su columna «Ocios de un médico»».

Publicó numerosos artículos en distintas revistas profesionales como El Siglo Médico, España Médica, Archivos Españoles de Tisiología, o Revista General de Medicina y Cirugía, en la que aparece entre los colaboradores permanentes. Además, encontramos también numerosos trabajos suyos en Galicia Médica, Boletín del Dispensario Antituberculoso, Galicia Clínica y Revista Médica Gallega ${ }^{18}$.

Éstas son algunas de las publicaciones de Enrique Hervada:

- La alimentación (1908).

- Las enfermedades venéreas (1909).

- La alimentación del sano y del enfermo (1914).

- Un caso de miasis cutánea (1920).

- Indicaciones del pneumotórax artificial en las hemoptisis tuberculosas (1921).

- El problema social de la tuberculosis. La vida escolar. (1922).

- Lo que todos debemos saber de la tuberculosis (1922).

- Reumatismo tuberculoso articular y abarticular (1922).

- Sanatorios de montaña para los tuberculosos pulmonares, durante la buena estación, en comarcas de Galicia adecuadas por su orografía y facilidades de acceso y avituallamiento. Ponencia presentada en el Primer Congreso de Lucha Antituberculosa de la Toja (1925).

- La tuberculosis en Galicia (1925-1926).

- Consultas Médicas Frecuentes (1928).

- Los dolores braquiales de origen cerebral (1929).

- Pseudo tuberculosis pulmonar de origen cardíaco (1929).

- Actinomicosis pulmonar (1930).

- Las manifestaciones abdominales de la bacilosis latente (1930).

- Estigmas somáticos de origen tuberculoso. Infantilismo (1931).

- Prontuario farmacológico. Verdadero formulario de bolsillo (1931).

- Eventración diafragmática (1931).

- El tratamiento del asma por la tuberculina (1932).

- Sobre la etiología sifilítica de la esclerosis en placas (1932).

- Los síntomas que molestan al tuberculoso (1933).

- Tratamiento sintomático de la tuberculosis pulmonar (1934).

- Fiebre y febrícula de origen tuberculosa (1948).

- Epidemias silenciosas (1953).

\footnotetext{
17 Antón CAPELÁn ReY, "Contribucións a unha historia da Universidad Popular da Coruña”, Sarmiento, Anuario Galego de Historia da Educación, 3 (1999).

18 Bugallo, "Enrique Hervada García-Sampedro", [Consulta: 19/03/2017].
} 
Vemos, por tanto, que además de su constante actividad profesional en su consultorio privado, en el Dispensario antituberculoso y en Sanatorio Marítimo de Oza, el Dr. Hervada dedicaba tiempo a realizar numerosas publicaciones y desarrollar una importante labor como divulgador y conferenciante.

Muchas de estas publicaciones, eran compartidas por el Dr. Hervada con la población coruñesa en la Reunión Recreativa e Instructiva de Artesanos, también llamada, coloquialmente, Circo de Artesanos, órgano sociocultural de las clases trabajadoras ${ }^{19}$.

Eran charlas y conferencias que Enrique Hervada impartía gratuitamente para instruir a la población en materia de higiene, alimentación, tuberculosis,

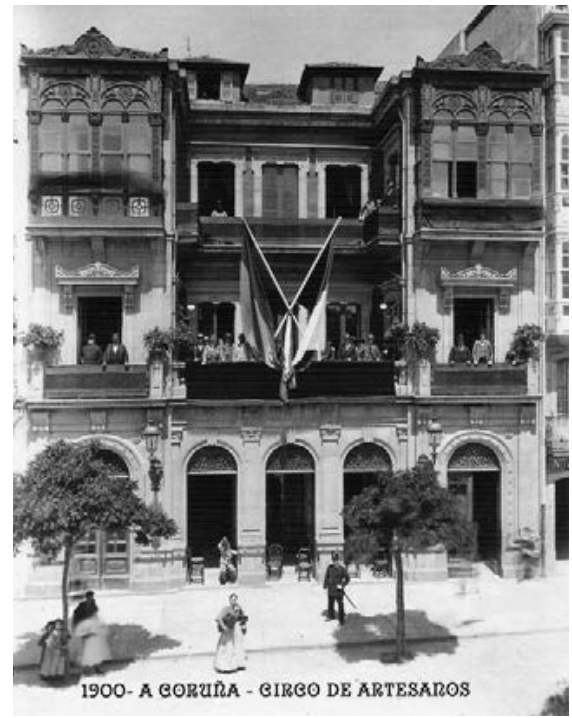

Fig. 2. Circo de Artesanos de A Coruña . Imagen obtenida de: https://deandanzasyrelatos.wordpress.com/ category/a-coruna-de-ayer-a-hoy/. sífilis, etc.

Era tal su implicación en esta Sociedad, que, en 1909, lo nombraron Vicepresidente, y, en 1922, Presidente.

El año de presidencia del Dr. Hervada fue muy importante para el prestigio de la Reunión Recreativa, por la altura y cantidad de sus múltiples conferencias, actos científicos y solemnidades literarias.

Era, además, esta Sociedad la que albergaba la Biblioteca de la Universidad Popular $^{20}$, siendo Enrique Hervada uno de los promotores de esta Universidad, junto a otros muchos notables de la ciudad como Manuel Monteagudo, Santiago Casares Quiroga, Alberto Insúa, Wenceslao Fernández Flórez, etc.

\footnotetext{
${ }^{19}$ Félix Estrada Catoyra, Contribución a la historia de La Coruña: la Reunión Recreativa e Instructiva de Artesanos en sus ochenta y tres años de vida y actuación 1853-1938, La Coruña, Tip. El Ideal Gallego, 1930 .

${ }^{20}$ Sobre esta biblioteca cuenta Rof Carballo, el gran médico español pionero de la medicina psicosomática, hijo del muy destacado veterinario Rof Codina, que era una biblioteca llena de tesoros, donde pasaba horas deliciosas siendo joven y que un día inquietó a sus padres porque llegó tarde a casa, tras pasarse cuatro horas leyendo de un tirón poesías de Lord Byron. Vid. Fernando Ponte Hernando, El concepto «Un mundo, una salud», en los inicios del siglo XX: el Dr. D. Marcelino Ramírez García (1864-1940) veterinario militar y médico, Cáceres, Universidad de Extremadura, Facultad de Veterinaria, tesis doctoral, [2019], pág. 152.
} 
Dentro de las actividades llevadas a cabo en esta Universidad Popular, destacaban sobre todo cursos y conferencias de distintas materias. El destinatario de la labor docente de la Universidad Popular coruñesa fue, fundamentalmente, el proletariado urbano, adscrito a las diferentes sociedades de defensa de orientación anarcosindicalista o socialista.

Se impartían cursos de dos o seis horas a la semana de varias materias: Aritmética en varios grados, Geometría, Dibujo métrico, Caligrafía, Ortografía y Redacción, Francés, Inglés, etc. ${ }^{21}$.

Fueron muchos los conferenciantes que pasaron por esta Universidad: Ortega y Gasset, Nóvoa Santos, Gil Casares, Gordón Ordás, Marcelino Ramírez y, entre ellos, Hervada que impartió las siguientes charlas:

- 1906 : Alcoholismo

- 1907: Higiene de la Alimentación

- 1907: La alimentación

- 1909: Las enfermedades venéreas

- 1910: «606»

- 1914: La alimentación del sano y del enfermo

- 1927: Lo que vemos por los Rayos x

La Universidad Popular elaboró e imprimió distintos folletos didácticos de cada una de estas conferencias, con su rúbrica, para repartir, gratuitamente, entre todos los asistentes.

De los dos primeros folletos del Dr. Hervada se hicieron tres ediciones, lo que pone de manifiesto el interés que despertaban sus charlas entre los coruñeses.

A partir de 1920 y hasta días antes de fallecer, Enrique Hervada colabora muy activamente en la Real Academia de Medicina de Galicia y Asturias.

Presentó su discurso de ingreso La Tuberculosis Obscura, en el que relata algunos casos asistidos por él durante quince años de labor asistencial realizada a pacientes tísicos y sifilíticos.

Durante este tiempo hizo un importante e intenso trabajo de observación médica, en la que destaca los numerosos casos que no tienen una sintomatología clara de tuberculosis y pasan desapercibidos o diagnosticados de forma errónea, por lo que concluye animando a todos los presentes en su discurso a prestar atención a la sintomatología bacilar latente que puedan presentar sus pacientes, ya que se beneficiarán del tratamiento oportuno y a su debido tiempo, contribuyendo así a la lucha antituberculosa.

\footnotetext{
21 “La Universidad Popular”, La Voz de Galicia (19-06-1912).
} 
Contribuye a la vida de la institución con numerosas conferencias y participa con intensidad en las actividades llevadas a cabo.

Éstas son algunas de las conferencias impartidas por el Dr. Hervada a las que tuvimos acceso :

- Los dolores braquiales de origen cerebral.

- Las manifestaciones abdominales de la bacilosis latente.

- Estigmas somáticos de origen tuberculoso. El Infantilismo.

- Los síntomas que molestan al tuberculoso.

- Fiebre y febrícula de origen tuberculoso.

Es en 1933, cuando ocupa el cargo de Secretario Perpetuo, tal y como recoge José Carro Otero, en su libro de la Real Academia de Medicina y Cirugía de Galicia.

Ocupará este cargo hasta su fallecimiento, en 1953. Por lo que serán desde su ingreso en 1920, 33 años de importante contribución a esta Institución.

ESTUDIO EPIDEMIOLÓGICO REALIZADO EN GALICIA POR EL DR. HERVADA: LA LUCHA ANTITUBERCULOSA EN GALICIA

El Dr. Hervada dedicó especial interés al estudio de la tuberculosis. En el primer tercio del siglo XX realizó el mayor estudio epidemiológico sobre tuberculosis en Galicia. Lo llevó a cabo a través de entrevistas a decenas de médicos rurales, y lo publicó en 1924 como La lucha antituberculosa en Galicia (1923). En este estudio recogió mapas de mortalidad por cada 1000 habitantes en 1921 y analizó, mediante gráficas, la evolución de la enfermedad de 1910 a 1921; exponía también que la lucha antituberculosa preventiva debía orientarse en Galicia hacia el problema de la herencia y de la emigración.

Hervada analizaba, de forma muy completa, la incidencia, etiología y mortalidad por tuberculosis en Galicia, entre 1910 y 1921. Su estudio epidemiológico sirvió de referencia para numerosos tisiólogos.

Decía que resultaba muy complicado fijar, con precisión, la mortalidad global por tuberculosis, ya que, en numerosas ocasiones, no se hacía un diagnóstico correcto de la enfermedad y en lo que se recogía como bronquitis, congestiones pulmonares, neumonías, meningitis, etc. se ocultaba, realmente, la enfermedad tuberculosa.

En el año 1920, hubo en Galicia un total de 44.697 defunciones a consecuencia de diversas enfermedades. De esta cifra corresponde a la tuberculosis 3.695, repartidas en la siguiente forma:

La Coruña: 1.754 
Lugo: 752

Orense: 385

Pontevedra: 1.101

Si miramos las columnas de otras defunciones, es fácil comprender que del crecido número de muertes por meningitis simple, bronquitis aguda, bronquitis crónica, pneumonía, diversas afecciones del aparato respiratorio, cirrosis hepática y otras enfermedades, hay que entresacar bastante número para la casilla de tuberculosos. Así vemos, que en el libro de Registro Civil de Villaodrid ${ }^{22}$ (Lugo) no aparece ninguna certificación por tuberculosis en todo el año 1921, a pesar de ser un Ayuntamiento de más de 4.000 habitantes; en cambio, hay registradas defunciones por meningitis, bronquitis crónica, etc. Tenemos pues, sobrado fundamento para decir que, desgraciadamente, no pecamos de exagerados al contar que Galicia tiene un promedio anual de 7.000 víctimas causadas por la bacilosis, y que, por lo tanto, existen en nuestra bella región 70.000 enfermos tuberculosos.

[.....] En nuestro mapa, hecho con los datos oficiales, llama la atención la diferencia de mortalidad de tuberculosis en distintos puntos, con diferencias tan grandes en algunas, como Arzúa y Becerreá, por ejemplo, que siendo ambos sitios montañosos, con igual clima, alimentación, costumbres, etc., en Arzúa contamos 16,24 de mortalidad tuberculosa por 1.000 habitantes, mientras que en Becerreá no aparece ninguna defunción por esta causa. Esta diferencia en realidad, no existe, no puede existir; es más, tenemos la casi seguridad de que hay en los dos Ayuntamientos el mismo porcentaje de mortalidad bacilar (aunque no lo creemos tan elevado como figura en Arzúa), pero lo hacemos constar oficialmente para no desviarnos, como hemos dicho de los datos estadísticos registrados ${ }^{23}$.

Recogió en su estudio los datos que hacían referencia al número de defunciones causadas por la tuberculosis en Galicia desde el año 1910 a 1921, mediante las citadas encuestas enviadas a los médicos rurales, preguntando acerca de la incidencia, posible etiología y causas de fallecimiento:

\footnotetext{
22 A Pontenova es un municipio de la provincia de Lugo. Pertenece a la comarca de La Mariña Oriental. Hasta el año 1951 se llamó Villameá. En el año 1963 se fusiona con el municipio de Villaodrid adoptando el nombre de Puente Nuevo-Villaodrid.

${ }^{23}$ Enrique Hervada, La lucha antituberculosa en Galicia, La Coruña, Tipografía del Noroeste, 1924.
} 


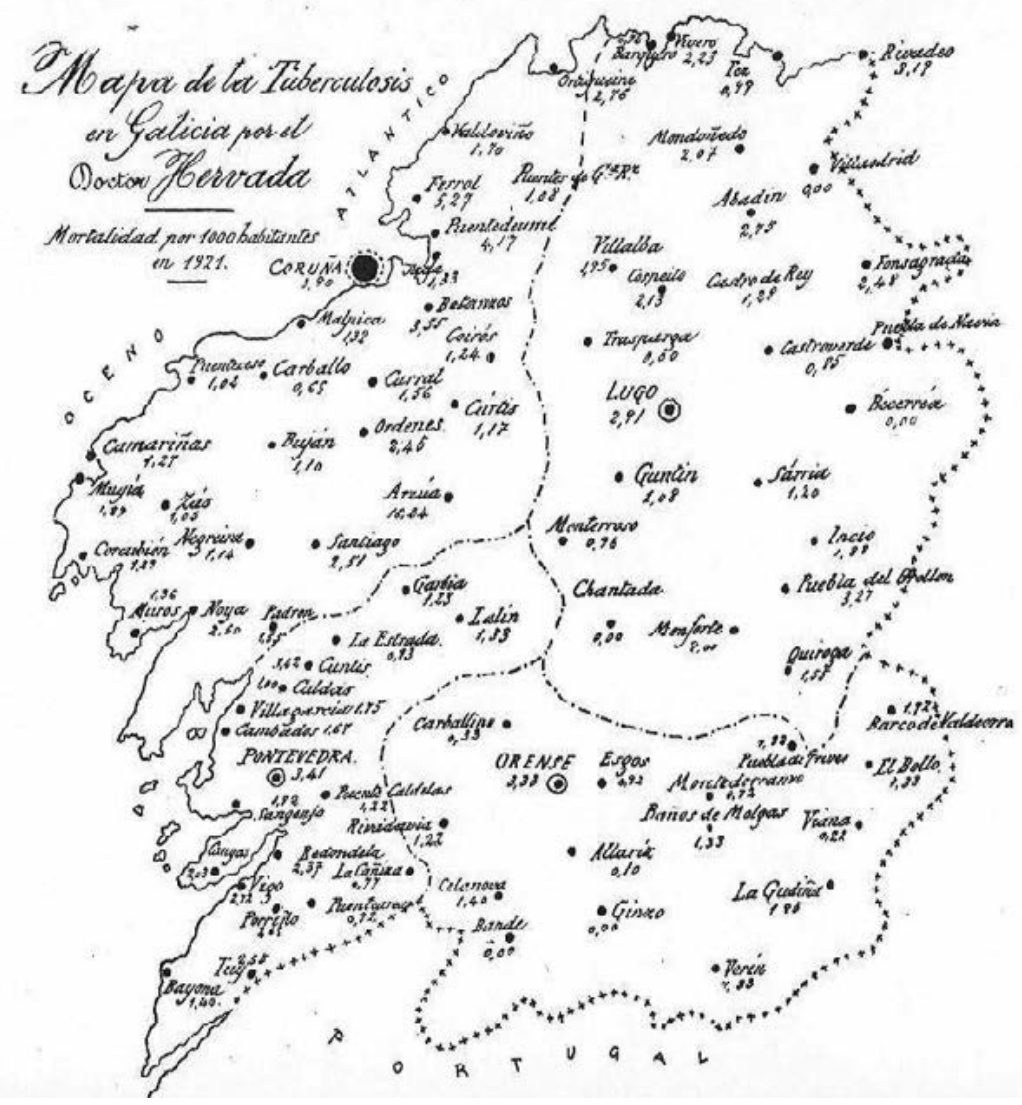

Mapa. 1. Mortalidad por tuberculosis en Galicia en 1921. Enrique Hervada. Publicado en La lucha antituberculosa en Galicia, año 1924.

Enrique Hervada había sido designado relator en el I Congreso de Reorganización Sanitaria para desarrollar el tema de Adaptación de la lucha antituberculosa según los caracteres de la región gallega.

Ante el aplazamiento indefinido del Congreso, Hervada decidió utilizar esas notas recogidas para él, que le fueron muy útiles para desarrollar una labor estadística y comenzar las bases de la lucha en la región gallega y poder publicar su gran estudio epidemiológico.

En el desarrollo del estudio, trató detalladamente estos temas:

- Geografía y climatología de la región. Clima Marino.

- Tuberculosis en Galicia

- La herencia y el contagio en Galicia 
- La emigración

- La alimentación

- El alcoholismo

- Las industrias

- La tuberculosis latente

- El actual armamento antituberculoso en Galicia

- Colonias escolares para niños pretuberculosos

- Dispensarios antituberculosos

- Sanatorio Marítimo de Oza

- Conclusiones

El clima gallego fue muy estudiado por numerosos tisiólogos, gallegos y de toda España, en cuanto a la prevención y curación de la tuberculosis.

Para Hervada, en las costas gallegas existían las mismas formas tuberculosas que en el interior y que en otras regiones de España y del extranjero, aunque matizaba lo siguiente:

Aunque luego veremos por los datos estadísticos, que la mortalidad por tuberculosos es mayor en las costas, hay que achacar exclusivamente este aumento a la cantidad enorme de bacilares que origina la emigración ${ }^{24}$.

No creemos, como Martín Salazar, que las condiciones climatológicas del Norte influyan en el desarrollo del bacilo, pues muchas regiones de nuestra costa, como Bares, El Grove y Corcubión, tienen escasa o nula mortalidad por tuberculosis, y en cambio algunas regiones del interior dan un tanto por ciento más elevado.

Conocemos muchos ancianos que viven en La Coruña y están clínicamente curados, en los cuales se notan aún signos físicos de sus antiguas lesiones. Vemos sobradamente bastantes formas abortivas. Tratamos también muchos bacilares crónicos y ultracrónicos, que a pesar de estar alejados de todo principio higiénico no se modifica desfavorablemente la marcha tórpida de la infección.

En algunas formas fibrocaseosas no hemos visto detección del proceso....en cambio en otras, comprendimos la enorme utilidad sacada al cambio del clima.

Claro está que, a pesar de la benignidad de nuestro clima, es muy dificil hacer cura de aire durante el invierno, por la intensidad de

\footnotetext{
${ }^{24}$ Hervada, La lucha antituberculosa ..., pág. 78.
} 
los vientos o por las abundantes lluvias; pero también hemos de reconocer por las comparaciones meteorológicas de otros puntos, que estamos en casi igualdad de condiciones y con una ventaja a nuestro favor por lo que se refiere a la temperatura ${ }^{25}$.

Peña Novo defendía las condiciones climáticas y geográficas gallegas, al igual que lo hacía Hervada, y, además, estaba plenamente convencido de la necesidad de la construcción en Galicia de sanatorios para el tratamiento de los tuberculosos ${ }^{26}$.

\section{La Emigración como fuente de tuberculosis ${ }^{27}$}

Otro de los puntos calientes en el estudio del desarrollo y propagación de la tuberculosis, fue la emigración.

En opinión de Hervada, la emigración era un problema muy importante a tener en cuenta como causa frecuente de la tuberculosis. Coincidía en esto con la opinión de su amigo Miguel Gil Casares ${ }^{28}$, catedrático de Clínica Médica en la Universidad de Santiago.

Así lo relata en su estudio, tomando en consideración todas esas encuestas y entrevistas:

Nos escriben todos los médicos en parecidos términos: la tuberculosis, muy rara hace treinta años, es hoy relativamente frecuente y es de ordinario importada por los que regresan de América y por el soldado, sobre todo, por el que hace el servicio en la Armada.

Los primeros datos estadísticos más allá de simples observaciones epidemiológicas que revelan una mayor incidencia de enfermedad tuberculosa en la población gallega que en el resto del estado en la época de Gil Casares pertenecen al quinquenio 1907-1911. Son el resultado de un estudio realizado por el Dr. Clavijo y Clavijo, quien compara la aparición de la enfermedad en los apostaderos de Cádiz, Cartagena y Ferrol, según el lugar de origen de los declarados afectos por tuberculosis en la Marina de Guerra.

\footnotetext{
${ }^{25}$ Hervada, La lucha antituberculosa ..., pág. 112.

26 Plácido PEÑa Novo, El problema tuberculoso en Galicia, La Coruña, Imprenta Moret,1930.

27 José Souto Beavís; Julio Freijanes Malingre; Germán Alonso Hortas; Enrique Hervada García SAMPEDRo, "Problemas sanitarios que plantea la emigración e inmigración en Galicia", Galicia Clínica, año 5, núm. 8 (1933), págs.. 365-391.

${ }^{28}$ Miguel Gil CASAREs, "La herencia y el contagio de la tuberculosis pulmonar y de la lepra en Galicia", Santiago, Tip. E1 Eco Franciscano, 1912.
} 
Como se puede observar la afectación entre los gallegos es significativamente mayor que la de otras regiones, datos que de entrada contrastan con los que se recogen de la población general. Ignoramos a qué se pueden deber tales diferencias pero imaginamos que debe ser de origen multifactorial: clase social, alimentación previa, mayor reclutamiento entre la población gallega ${ }^{29}$.

Para intentar demostrar la influencia de la emigración en el desarrollo y evolución de la tuberculosis, el tisiólogo coruñés elaboró un cuestionario que le haría llegar a un gran número de médicos de toda Galicia, tanto de la costa como del interior.

Los resultados de dichas encuestas aparecen recopilados en su obra La lucha antituberculosa en Galicia. De los 43 ayuntamientos de los que recogió la situación de la tuberculosis, 17 alegaban el retorno migratorio como causa fundamental, o una de las fundamentales, para motivar ese aumento de incidencia.

\section{La alimentación y su relación con la tuberculosis}

La alimentación era otro tema importante en su estudio, ya que decía que, consecuencia directa de la penuria económica del obrero era la mala alimentación que conducía a la miseria orgánica, terreno abonado para que se desarrollara la tuberculosis. Al poco poder adquisitivo de los obreros se unía la adulteración de alimentos y bebidas que, según se estimó, alcanzaba al 55\% de los ultramarinos puestos al consumo ${ }^{30}$.

Una alimentación abundante y equilibrada era la base para tratar cualquier enfermedad y, por supuesto, la tuberculosis. En esto estaban prácticamente de acuerdo todos los tisiólogos.

El problema que existía en Galicia durante el primer tercio del siglo XX era que la alimentación era muy escasa y poco variada.

Hervada opinaba que era fundamental una buena alimentación, tanto para los sanos como para los enfermos.

\section{Higiene, sol y reposo}

Según él, las claves fundamentales para la lucha antituberculosa eran: reposo, limpieza personal y de locales, aireación, pocos vicios, luz solar en abundancia, gimnasia respiratoria y sobrealimentación.

\footnotetext{
29 Salvador Clavijo y Clavijo, Tuberculosis en la Marina de guerra. (Nuevas orientaciones y reformas), Madrid, Imprenta del Ministerio de Marina, 1914.

${ }^{30}$ Antonio Espina y CAPó, Congreso nacional da la tuberculosis celebrado en Zaragoza, del 2 al 6 de octubre de 1908, Madrid, Imp. Nicolás Moya, 1909, pág. 21.
} 
Así lo puso de manifiesto en este trabajo realizado durante 1925-1926:

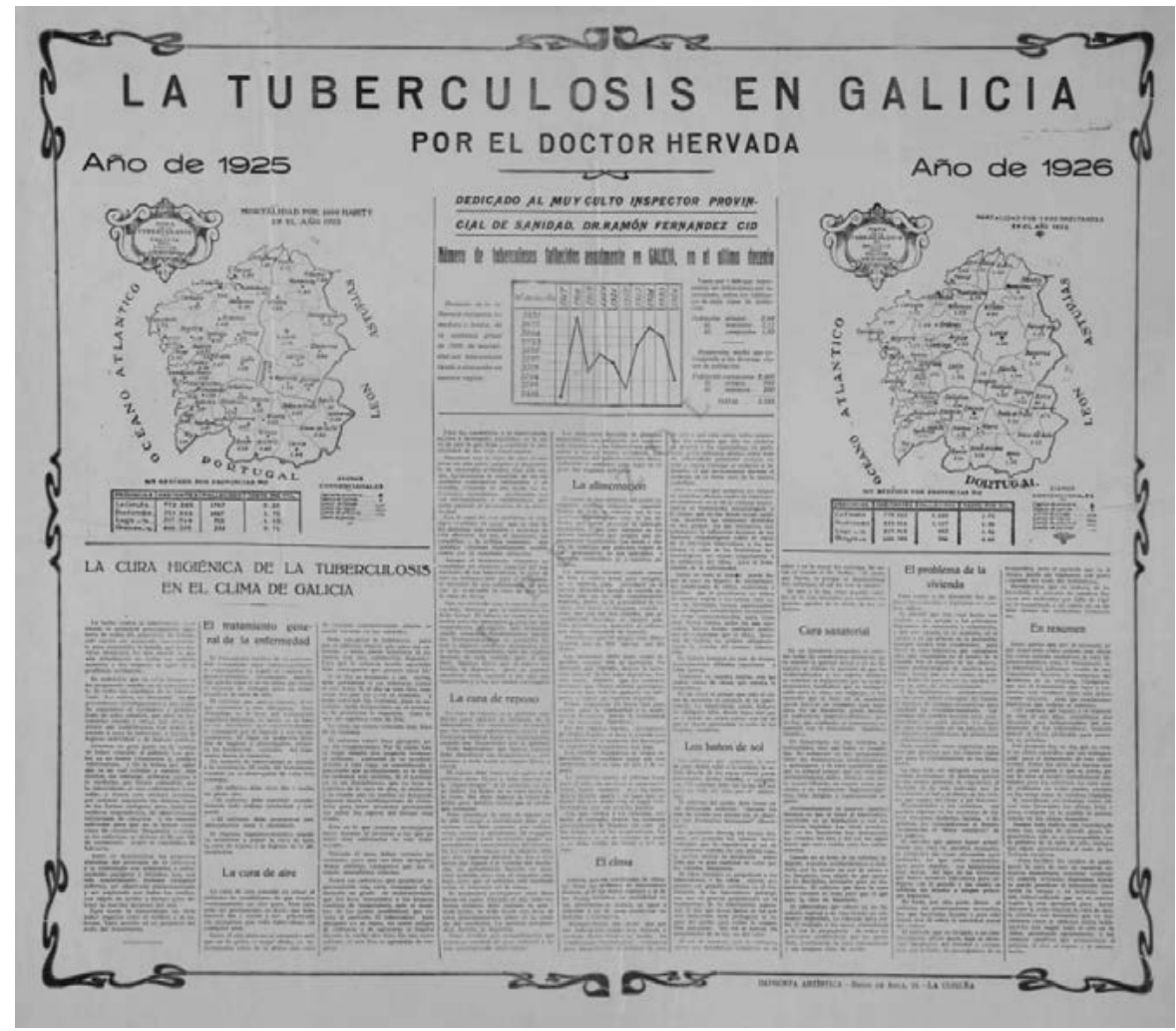

Fig. 3. La tuberculosis en Galicia. Publicado en Enrique Hervada García Sampedro, La tuberculosis en Galicia, A Coruña, Imp. Artística, [s. a].

La actividad divulgadora de Enrique Hervada García Sampedro fue incansable para intentar que las clases sociales más desfavorecidas no se viesen tan azotadas por la llamada «peste blanca». Demostró, en su estudio, cómo una buena educación higiénico-sanitaria, sobre todo a nivel doméstico, disminuía notablemente los casos de tuberculosis.

Además, defendía, fervientemente, las colonias escolares para niños pretuberculosos y tuberculosos como medio de educación, los dispensarios antituberculosos como organismo de profilaxis social, y los Sanatorios para casos en los que la tuberculosis necesitaba tratamiento, a medio y largo plazo, e incluso, cirugía. 


\section{DESPEDIDA A ENRIQUE HERVADA: EL MÉDICO DEL PUEBLO CORUÑÉS}

El día 3 de abril de 1953, viernes santo, a consecuencia de una encefalitis vírica, breve y gravísimo proceso, que le había contagiado un paciente, al que le diagnosticó la enfermedad, fallecía el Dr. Hervada a los 69 años, dos meses antes de cumplir los 70 .

La Coruña, su ciudad natal, supo estar a la altura de las circunstancias. El pueblo se entregó a quien en vida le sirvió con su ciencia, su humanidad y su campechanía. Por ello el féretro salió de la calle Real a hombros, a pesar de que las autoridades lo prohibían, hasta el cementerio de San Amaro donde sería enterrado, y por la calle Bailén y la de Panaderas fue seguido por un enorme gentío.

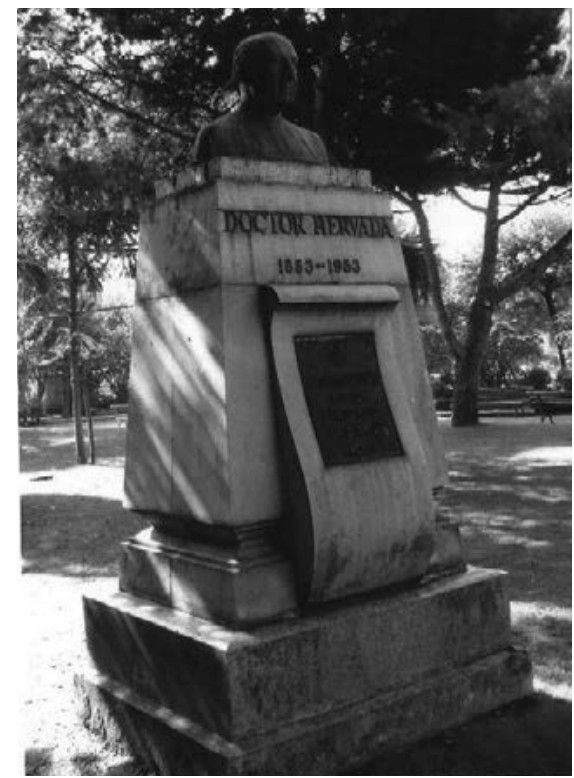

Fig. 4. Busto de Enrique Hervada en los jardines de Méndez Núñez. La Coruña. Cedida por el Dr. Arturo Rodríguez Hervada.

En la plaza de España y la calle de la Torre y en San Amaro se sumó otra enorme multitud al sepelio.

El Ayuntamiento dedicó una calle a la memoria de este insigne médico en el barrio de Cuatro Caminos y le erigiría un monumento en los jardines de Méndez Núñez un año más tarde.

Fueron numerosos los artículos necrológicos que se escribieron a raíz de su muerte. Entre sus autores destacamos los siguientes: Joaquín García Morán, Aurelio Gutiérrez Moyano, Eduardo Pérez Hervada, Jerónimo Sal Lence, Galo García Baquero...Todos ellos aportan multitud de aspectos de la persona y obra de Enrique Hervada García-Sampedro. Además de las cartas que hicieron llegar a su familia numerosos amigos como: Gregorio Marañón, Jiménez Díaz, Fernández Florez...

\section{BIBLIOGRAFÍA}

Bugallo, Ánxela, "Enrique Hervada García-Sampedro", en Álbum da Ciencia, Culturagalega. org. Consello da Cultura Galega, 2012.<http://www.culturagalega.org/albumdaciencia/ detalle.php?id=251>. [Consulta: 19/03/2017].

Capelán Rey, Antón, "Contribucións a unha historia da Universidad Popular da Coruña", Sarmiento, Anuario Galego de Historia da Educación, 3 (1999), págs. 25-63. 
Carro Otero, José, Real Academia de Medicina y Cirugía de Galicia, A Coruña, Ed. RAMYCGA, 2002.

Clavijo y Clavijo, Salvador, Tuberculosis en la marina de guerra. Nuevas orientaciones y reformas, Madrid, Imprenta del Ministerio de Marina, 1914. "Conferencia del Dr. E. Hervada", El Diario de Pontevedra (02-11-1910), pág. 2. "Conferencia del Dr. E. Hervada", La Región (01-11-1910), pág.1.

Espina Capó, Antonio, Congreso nacional da la tuberculosis celebrado en Zaragoza, del 2 al 6 de octubre de 1908, Madrid, Imp. Nicolás Moya, 1909.

Estrada Catoyra, Félix, Contribución a la historia de La Coruña: la Reunión Recreativa e Instructiva de Artesanos en sus ochenta y tres años de vida y actuación 1853-1938, La Coruña, Tip. El Ideal Gallego, 1930.

Gaceta de Galicia. Diario de Santiago (07-06-1903), pág. 2.

Gil Casares, Miguel, "La herencia y el contagio de la tuberculosis pulmonar y de la lepra en Galicia”, Santiago, Tip. El Eco Franciscano, 1912.

González Castroagudín, Sonia, Sifilis, tuberculosis y alimentación, la obra de Enrique Hervada García Sampedro (1883-1953) y la salud materno - infantil, Universidade da Coruña, 2017, tesis de doctorado inédita, disponible en $<$ https://ruc.udc.es/dspace/handle/2183/19155>.

González Catoyra, Alfonso, Biografias coruñesas, La Coruña, Graf. Galaico, 1990.

Hervada García Sampedro, Enrique, La tuberculosis en Galicia, A Coruña, Imp. Artística, [s. a]. Hervada, Enrique, La lucha antituberculosa en Galicia, La Coruña, Tipografía del Noroeste, 1924.

Hervada, Enrique, La Región (05-05-1911), pág. 3.

Hervada, Enrique. "La Universidad Popular", La Voz de Galicia (19-06-1912).

Hervada, Enrique, “Nombramientos”, El Norte de Galicia. Diario politico y de información (29-08-1908), pág. 2.

Hervada, Enrique, "Nuevo tratamiento de la sífilis", La Región, Diario independiente (20-101910), pág.3.

Peña Novo, Plácido, El problema tuberculoso en Galicia, La Coruña, Imprenta Moret,1930.

Pérez-Albacete, M., "Joaquín María Albarrán y Domínguez (1860-1912), En el centenario de su fallecimiento", Actas urológicas españolas, vol. 36, núm. 4 (2012), págs. 246-251.

Ponte Hernando, Fernando, El concepto «Un mundo, una salud», en los inicios del siglo XX: El Dr. D. Marcelino Ramírez García (1864-1940) veterinario militar y médico, Cáceres, Universidad de Extremadura, Facultad de Veterinaria, tesis doctoral en prensa, 2019.

Real, Ángel, "El circo perdido", De andanzas y relatos [en línea], disponible en $<\mathrm{https} / /$ deandanzasyrelatos.wordpress.com/2016/11/28/el-circo-perdido/> [Consulta: 24/09/2018].

Rodríguez Hervada, Arturo, Del tiempo de los odios y las iras. La educación de un niño de la guerra civil, 1936-1956, [s. 1.], Ed. Bubok, 2009.

Souto Beavís, José; Freijanes Malingre, Julio; Alonso Hortas, Germán; Hervada García Sampedro, Enrique, "Problemas sanitarios que plantea la emigración e inmigración en Galicia", Galicia Clínica, año 5, núm. 8 (1933), págs. 365-391. 